\title{
Overexpression of EphB4 promotes neurogenesis, but inhibits neuroinflammation in mice with acute ischemic stroke
}

\author{
JIN WANG ${ }^{1}$, ZUN ZHANG $^{2}$, SHAOJING FU $^{1}$, XIAOJIE LI ${ }^{1}$, XINHUI LI $^{3}$, SHAOBIN WANG $^{1}$ and LIHE YUAN ${ }^{1}$ \\ Departments of ${ }^{1}$ Neurology and ${ }^{2}$ Orthopedics, Inner Mongolia Baogang Hospital, Baotou, Inner Mongolia 014010; \\ ${ }^{3}$ Department of Neurology, First Affiliated Hospital of Baotou Medical College, Baotou, Inner Mongolia 014016, P.R. China
}

Received January 22, 2021; Accepted June 10, 2021

DOI: $10.3892 / \mathrm{mmr} .2021 .12396$

\begin{abstract}
Ischemic stroke is one of the most common diseases that has a high rate of mortality, and has become a burden to the healthcare system. Previous research has shown that EPH receptor B4 (EphB4) promotes neural stem cell proliferation and differentiation in vitro. However, little is known regarding its role in the neurogenesis of ischemic stroke in vivo. Thus, the present study aimed to verify whether EphB4 was a key regulator of neurogenesis in ischemic stroke in vivo. Cerebral ischemia was induced in $\mathrm{C} 57 \mathrm{BL} / 6 \mathrm{~J}$ mice via middle cerebral artery occlusion (MCAO), followed by reperfusion. Immunofluorescence staining was performed to evaluate the effect of EphB4 on the neurogenesis in cerebral cortex. The levels of inflammatory cytokines were determined using an ELISA kit. The expression levels of ABL proto-oncogene 1, non-receptor tyrosine kinase (ABL1)/Cyclin D1 signaling pathway-related proteins were detected via western blotting. The current findings indicated that EphB4 expression was significantly increased in the cerebral cortex of MCAO model mice in comparison with sham-operated mice. Moreover, EphB4 appeared to be expressed in neural stem cells $\left(\mathrm{Nestin}^{+}\right)$, and persisted as these cells became neuronal progenitors $\left(\right.$ Sox $\left.2^{+}\right)$, neuroblasts [doublecortin $(\mathrm{DCX})^{+}$], and eventually mature neurons [neuronal nuclei $(\mathrm{NeuN})^{+}$]. Overexpression of EphB4 elevated the number of proliferating (bromodeoxyuridine $^{+}, \mathrm{Ki} 7^{+}$) and differentiated cells $\left(\mathrm{Nestin}^{+}\right.$, Sox $2^{+}$, $\mathrm{DCX}^{+}$and $\mathrm{NeuN}^{+}$), indicating the promoting effect of EphB4 on the neurogenesis of ischemic stroke. Furthermore, EphB4 overexpression alleviated the inflammation injury in MCAO model mice. The expression levels of proteins-related to the ABL1/Cyclin D1 signaling pathway were significantly increased by the overexpression of EphB4, which suggested that restoration of EphB4 promoted the activation of the
\end{abstract}

Correspondence to: Dr Lihe Yuan, Department of Neurology, Inner Mongolia Baogang Hospital, 20 Shaoxian Road, Kundulun, Baotou, Inner Mongolia 014010, P.R. China

E-mail: liheyuanok@126.com

Key words: $\mathrm{EPH}$ receptor $\mathrm{B} 4$, stroke, neurogenesis, $\mathrm{ABL}$ proto-oncogene 1, non-receptor tyrosine kinase/Cyclin D1 signaling
ABL1/Cyclin D1 signaling pathway. In conclusion, this study contributes to the current understanding of the mechanisms of EphB4 in exerting neurorestorative effects and may recommend a potential new strategy for ischemic stroke treatment.

\section{Introduction}

Stroke remains the second major cause of mortality worldwide and is the leading cause of death in China (1). According to a Global Burden of Disease study, there were 5.5 million deaths and 116.4 million disability adjusted life years due to stroke in 2017 (2). Although rapid progress has been achieved in the understanding of the pathogenesis of ischemic stroke, there is currently no effective therapeutic approach for nerve repair (3). Accumulating evidence has shown that cerebral ischemia can stimulate the activation of quiescent neural stem cells (NSCs) in the subventricular zone (SVZ) into transient amplifying progenitors, which become neuroblasts after several divisions $(4,5)$. The neuroblasts migrate into the damaged cortex and differentiate into mature neurons to promote the recovery of the neurological function (6). The growth peak of NSCs in the adult brain after ischemia is 7-10 days (7). However, this internal response cannot functionally compensate for the ischemic damage, and the migrating cells do not differentiate into mature neurons in the cortex $(8,9)$. Thus, it is critical to search for therapeutic approaches and specific targets to augment the differentiation of endogenous NSCs into neurons.

Neuroinflammation participates in the pathophysiological progress of secondary brain injury after ischemic stroke by increasing pro-inflammatory cytokines and neuronal apoptosis (10). A previous study has shown that the levels of inflammatory cytokines gradually increase within 0-24 h of cerebral ischemia reperfusion in rats, and reach a peak at $24 \mathrm{~h}$ (11). The interaction between neuroinflammation and subsequent neurogenesis remains unknown, and thus, has gained significant interest in recent years. Moreover, further understanding of neuroinflammation and its association with neurogenesis could provide a novel approach for brain repair.

Previous studies have reported that ephrin (Eph) receptors can regulate the proliferation of stem cells and progenitor cells in the central nervous system (CNS) (12). The Eph receptor family is the largest known receptor tyrosine kinase family. The members of this family bind their ligand ephrins to initiate bidirectional signaling and regulate different 
physiological activities, which have become popular research subjects internationally (13). Previous studies have shown that ephrinB/EphB signaling served an early role in the regulation of stem cell behavior. For instance, ephrinB3/EPH receptor B3 (EphB3) signaling exhibited an inhibitory effect on NSC proliferation in the developing SVZ (14). In the adult CNS, overexpression of ephrinB2 or EphB2 promotes NSC proliferation and represses neuroblast migration (15). However, research regarding EphB4 focuses on tumor cells. Restoration of EphB4 promotes tumor cell proliferation, migration and angiogenesis $(16,17)$. Moreover, a previous study revealed that EphB4 regulated the self-renewal, proliferation and neuronal differentiation of human embryonic NSCs in vitro (18).

The present study aimed to investigate the role of EphB4 in the neurogenesis and neuroinflammation of ischemic stroke in vivo.

\section{Materials and methods}

Animals and middle cerebral artery occlusion (MCAO) model. The animal experiment was approved by the Animal Care and Use Committee of Inner Mongolia Baogang Hospital (approval no. BG201802034YY). A total of 120 male C57BL/6J and EphB4 ${ }^{+}{ }^{+}$C57BL/6J mice (age, 6-8 weeks; weight, 21-23 g), bred by Cyagen Biosciences, Inc., were maintained on a 12-h light/dark cycle under specific pathogen-free conditions $\left(25^{\circ} \mathrm{C}\right.$; $50-70 \%$ humidity) with free access to food and water.

Transient MCAO was performed as previously reported (19), with a slight modification. The mice were randomly divided into four groups ( $\mathrm{n}=5 /$ group): Sham, EphB $4^{+} /+$Sham group, MCAO group and EphB4 ${ }^{+} /^{+} \mathrm{MCAO}$ group. Mice were anaesthetized with isoflurane (3\% induction; $1-1.5 \%$ maintenance) in a mixture of $75 \% \mathrm{~N}_{2} \mathrm{O}$ and $25 \%$ $\mathrm{O}_{2}$ and the rectal temperature was maintained at $37.0 \pm 0.5^{\circ} \mathrm{C}$. Then, the right common carotid artery and the right external carotid artery (ECA) were exposed. The ECA was then dissected distally, ligated and coagulated. The right MCA was occluded with a heparinized intraluminal filament (0.26 mm; rounded tip). After $30 \mathrm{~min}$ of ischemia, the intraluminal filament was withdrawn to accomplish reperfusion. The sham group underwent the same procedure without insertion of the intraluminal filament. After reperfusion for $1,3,7$ and 14 days, the mice were sacrificed with $120 \mathrm{mg} / \mathrm{kg}$ pentobarbital sodium via intraperitoneal injection. Death was ascertained based on pupil dilation and an inability to palpate the carotid pulse. Brain tissues were collected after the mice were sacrificed. Due to severe injuries, eight mice with rapid weight loss, loss of appetite or abnormal nervous system responses were euthanized with $2 \%$ pentobarbital sodium (120 mg/kg body weight).

\section{2,3,5-triphenyltetrazolium chloride (TTC) staining. TTC} staining was used to evaluate the infarct volume. Briefly, coronal brain slices $(2 \mathrm{~mm})$ were cut and immersed in $2 \%$ TTC solution for $30 \mathrm{~min}$ at $37^{\circ} \mathrm{C}$, followed by fixation in $4 \%$ paraformaldehyde overnight. The sections were photographed with a digital camera (Canon IXUS175; Canon, Inc.). The percentage of infarct area was calculated using Image $\mathbf{J}$ software 5.0 (National Institutes of Health).
Reverse transcription-quantitative PCR (RT-qPCR). Total RNA was extracted from cerebral cortex tissues using TRIzol ${ }^{\circledR}$ reagent (Invitrogen; Thermo Fisher Scientific, Inc.) according to the manufacturer's instructions. cDNA was synthesized according to the M-MLV conserved transcriptase instructions (Takara Biotechnology Co., Ltd.) using a PrimeScript ${ }^{\mathrm{TM}}$ RT reagent kit (Takara Bio, Inc.). RT was performed at $37^{\circ} \mathrm{C}$ for $15 \mathrm{~min}, 85^{\circ} \mathrm{C}$ for $5 \mathrm{sec}$, then $4^{\circ} \mathrm{C}$ for cooling. RT-qPCR was performed using a TB Green ${ }^{\circledR}$ Premix Ex Taq ${ }^{\mathrm{TM}}$ II kit (Takara Bio, Inc.). The thermocycling conditions were as follows: $20 \mathrm{sec}$ at $95^{\circ} \mathrm{C}$, followed by 40 cycles of $15 \mathrm{sec}$ at $95^{\circ} \mathrm{C}$ and $60 \mathrm{sec}$ at $60^{\circ} \mathrm{C}$, and $60^{\circ} \mathrm{C}$ for $1 \mathrm{~min}$. The data were normalized to the control and analyzed using the $2^{-\Delta \Delta \mathrm{Cq}}$ method (20). The primers used were as follows: EphB4 forward (F), 5'-CCC ATTTGAGCCTGTCAATGTC-3' and reverse (R), 5'-TCA AGCTGCTGGGTGAGGA-3'; ephrinB2 F, 5'-TATGCAGAA CTGCGATTTCCAA-3' and R, 5'-TGGGTATAGTACCAG TCCTTGTC-3'; and GAPDH F, 5'-CATGAGAAGTATGAC AACAGCCT-3' and R, 5'-AGTCCTTCCACGATACCAAA GT-3'. GAPDH was used as an internal reference.

Immunofluorescence analysis. Immunofluorescence staining was used to visualize nerve cells. Bromodeoxyuridine (Brdu; $50 \mathrm{mg} / \mathrm{kg}$; Sigma-Aldrich; Merck KGaA) was injected intraperitoneally into all mice twice daily for 4 consecutive days after MCAO. After being fixed with $4 \%$ paraformaldehyde at $37^{\circ} \mathrm{C}$ for $24 \mathrm{~h}$, brain tissue was embedded in paraffin and sectioned at a thickness of $5 \mu \mathrm{m}$. For Brdu staining, the sections were pretreated with $50 \%$ formamide, $280 \mathrm{mM} \mathrm{NaCl}$ and $30 \mathrm{mM}$ sodium citrate at $65^{\circ} \mathrm{C}$ for $2 \mathrm{~h}$, incubated in $2 \mathrm{M}$ $\mathrm{HCl}$ at $37^{\circ} \mathrm{C}$ for $30 \mathrm{~min}$ to denature the DNA and rinsed in boric acid $(0.1 \mathrm{M} ; \mathrm{pH} 8.5)$ at room temperature for $10 \mathrm{~min}$. After blocking the sections with 5\% donkey serum (Jackson ImmunoResearch Europe) for $2 \mathrm{~h}$ at room temperature, they were incubated for $48 \mathrm{~h}$ at $4^{\circ} \mathrm{C}$ with the following primary antibodies: Anti-EphB4 (Santa Cruz Biotechnology, Inc.; cat. no. sc-365510; 1:50), anti-Brdu (Abcam; cat. no. ab152095; 1:100), anti-Ki67 (Abcam; cat. no. ab15580; 1:200), anti-Nestin (Abcam; cat. no. ab105389; 1:250), anti-Sox2 (Abcam; cat. no. ab79351; 1:250), anti-doublecortin (DCX; Santa Cruz Biotechnology, Inc.; cat. no. sc-271390; 1:100) and anti-neuronal nuclei (NeuN; Abcam; cat. no. ab104224; 1:200). Subsequently, the sections were incubated with Alexa Fluor 488- or 594-conjugated secondary antibodies (Thermo Fisher Scientific, Inc.; cat. nos. A48269 and A11016; both 1:2,000) for $2 \mathrm{~h}$ at room temperature. The fluorescent images of cells were captured with a fluorescence microscope system (Nikon Eclipse 80i; Nikon Corporation; magnification, x200). In total, three areas of interest were selected around the margin of infarct area, and an average of the number of cells in the peri-infarct cortex for each section was obtained (21).

Western blotting. Total proteins were extracted from the infarct side of cerebral cortex with RIPA lysis buffer (Beyotime Institute of Biotechnology). BCA Protein Assay reagent (Beyotime Institute of Biotechnology) was applied to analyze proteins concentration. Proteins (50 $\mu \mathrm{g} /$ lane) were separated by $10 \%$ SDS-PAGE and transferred onto a nitrocellulose membrane. Subsequently, the membranes were blocked with $5 \%$ non-fat milk powder for $2 \mathrm{~h}$ at room temperature 
A

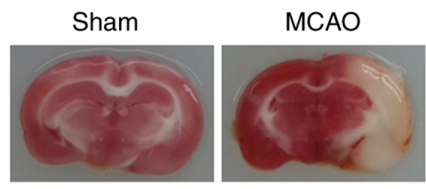

C
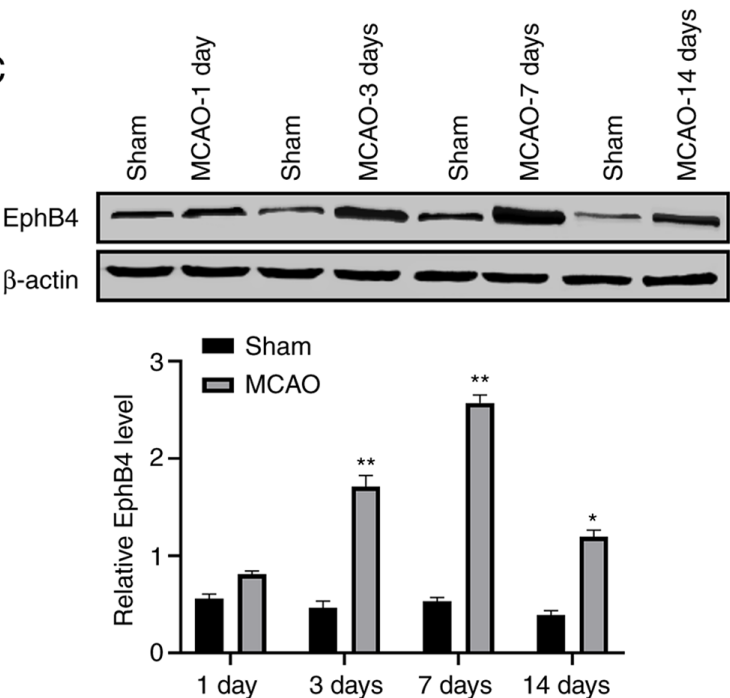

$\mathrm{B}$

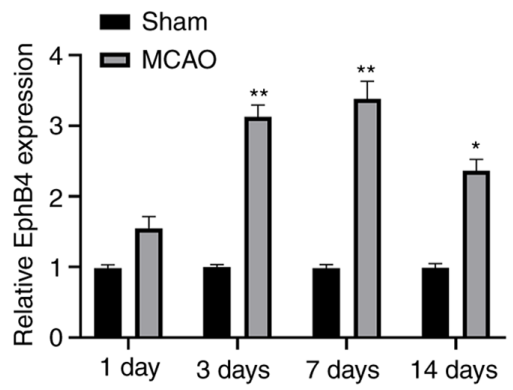

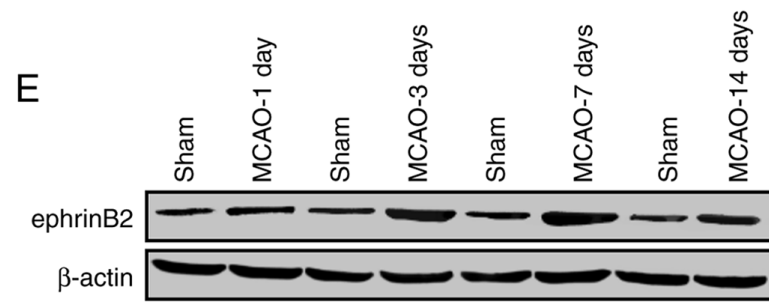

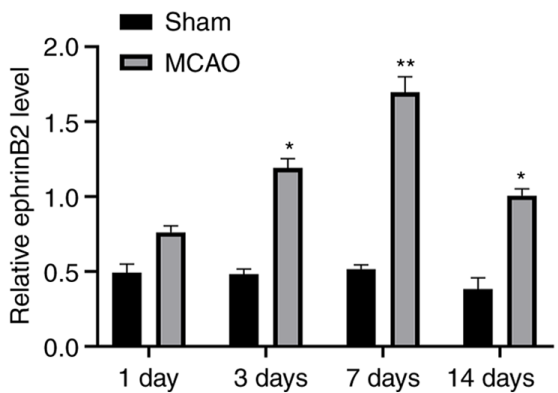

Figure 1. EphB4 is highly expressed in the cerebral cortex of MCAO model mice. (A) Representative images of cerebral infarctions were detected by TTC staining. (B) mRNA and (C) protein expression levels of EphB4, and the (D) mRNA and (E) protein expression levels ephrinB2 were detected in the cerebral cortex of mice after MCAO at 1, 3, 7 and 14 days via reverse transcription-quantitative PCR and western blotting. $n=5$ for each group. ${ }^{*} \mathrm{P}<0.05,{ }^{* *} \mathrm{P}<0.01 \mathrm{vs}$. Sham. MCAO, middle cerebral artery occlusion; EphB4, EPH receptor B4.

and incubated with primary antibodies, including anti-EphB4 (Abcam; cat. no. ab254300; 1:1,000), anti-ephrinB2 (Abcam; cat. no. ab75868; 1:500), anti-phosphorylated (p)-ABL proto-oncogene 1, non-receptor tyrosine kinase (ABL1; Cell Signaling Technology, Inc.; cat. no. 2864; 1:1,000), anti-ABL1 (Cell Signaling Technology, Inc.; cat. no. 2862; 1:1,000), anti-Cyclin D1 (Abcam; cat. no. ab134175; 1:2,000), anti-CDK4 (Abcam; cat. no. ab108355; 1:1,000) and $\beta$-actin (Abcam; cat. no. ab8227; $1: 1,000)$ at $4^{\circ} \mathrm{C}$ overnight, followed by the horseradish peroxidase-labeled secondary antibodies (Abcam; cat. nos. ab205718 and ab205719; both 1:2,000) at $37^{\circ} \mathrm{C}$ for $1 \mathrm{~h}$. The immunoreactive proteins were visualized using an ECL kit (MilliporeSigma) and the data were analyzed using ImageJ software (version 1.8.0; National Institutes of Health). The expression values were normalized against $\beta$-actin.

ELISA. The productions of IL-6, IL-1 $\beta$, TNF- $\alpha$, IL-10 and monocyte chemoattractant protein (MCP)-1 in the tissues and plasma of mice were measured using the corresponding mouse ELISA kits (cat. nos. RAB0314, RAB0274, RAB0477 and 
A

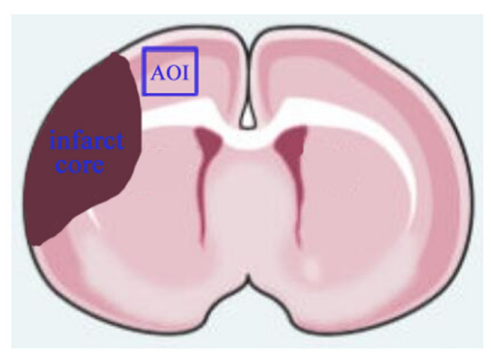

C
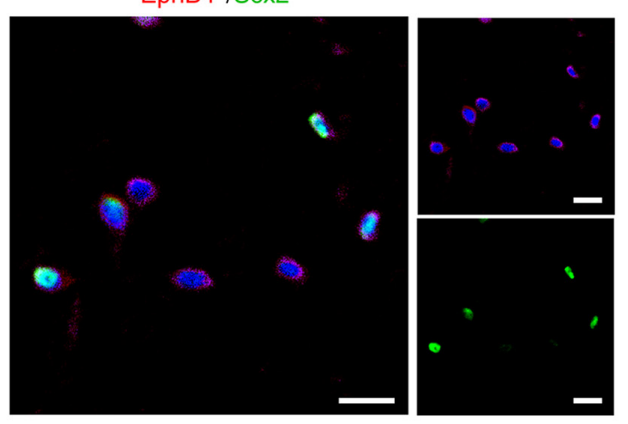

B

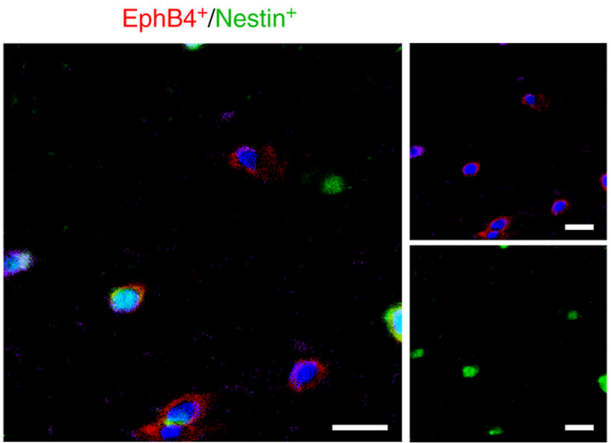

D

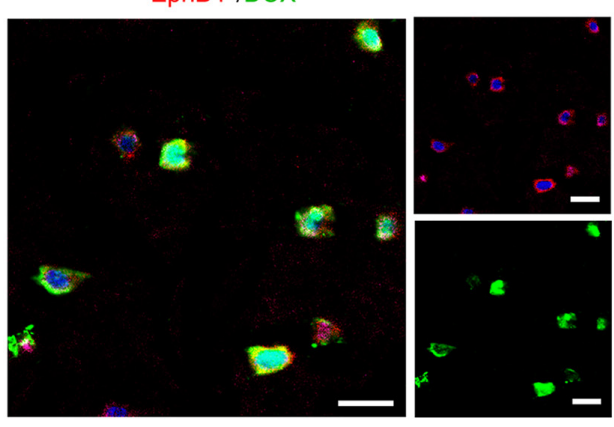

E

$\mathrm{EphB4}^{+} / \mathrm{NeuN}^{+}$
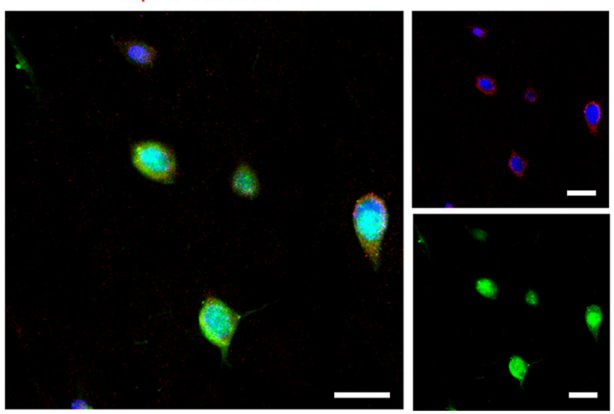

Figure 2. EphB4 is expressed in NSCs. (A) Blue boxes indicated AOIs in the peri-infarct cortex. Staining of the peri-infarct cortex revealed that (B) NSCs $\left(\right.$ Nestin $\left.^{+}\right)$expressed EphB4 and these expression persisted throughout NSC neuronal differentiation, including (C) neuronal progenitor (Sox $\left.2^{+}\right),(D)$ neuroblasts $\left(\mathrm{DCX}^{+}\right)$and (E) mature neurons $\left(\mathrm{NeuN}^{+}\right)$. Scale bar, $25 \mu \mathrm{m}$. AOI, area of interest; NSC, neuronal stem cell; DCX, doublecortin; EphB4, EPH receptor B4; NeuN, neuronal nuclei.

RAB0245, RAB0055, respectively; all Sigma-Aldrich; Merck $\mathrm{KGaA}$ ) following the manufacturer's instructions.

Statistical analysis. The data are presented as the mean \pm SD of five independent experiments. Statistical analyses were performed with SPSS 17.0 (SPSS, Inc.). One-way ANOVA followed by Tukey's post-hoc test was carried out to analyze multiple comparison, and unpaired Student's t-test was used to detect differences between two groups. $\mathrm{P}<0.05$ was considered to indicate a statistically significant difference.

\section{Results}

EphB4 is increased in the cerebral cortex of MCAO model mice. To evaluate the association of EphB4 with ischemic stroke, the expression levels of EphB4 and ephrinB2 in the cortex of MCAO model mice, followed by a reperfusion for 1, 3, 7 and 14 days, were detected. The TTC results confirmed the successful ischemia induction (Fig. 1A). The results from RT-qPCR assay demonstrated that the expression levels of EphB4 and ephrinB2 were increased after MCAO and peaked at 7 days (Fig. 1B and D), which was also confirmed by the results of western blotting assay (Fig. 1C and E).

EphB4 expression in nerve cells of the cerebral ischemic cortex. As reported in previous studies, in the cerebral cortex, NSCs express Nestin, the generated neuronal progenitors express Sox 2, neuroblasts express DCX and the mature neurons express NeuN $(22,23)$. In total, three areas of interest were selected around the margin of infarct area, and an average of the number of cells in the peri-infarct cortex for each section was calculated (Fig. 2A). The current immunofluorescence results identified that EphB4 was expressed by $\mathrm{Nestin}^{+}, \mathrm{Sox}^{+}, \mathrm{DCX}^{+}$ and $\mathrm{NeuN}^{+}$cells in the peri-infarct cortex of MCAO model mice (Fig. 2B-E). Moreover, EphB4 appeared to be expressed in NSCs $\left(\mathrm{Nestin}^{+}\right)$and persisted as these cells became neuronal 
A

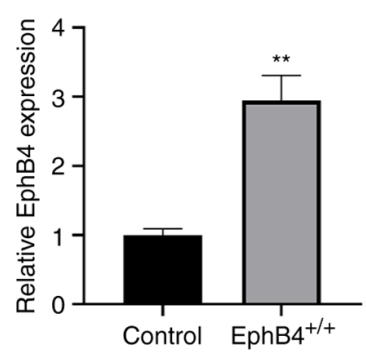

C
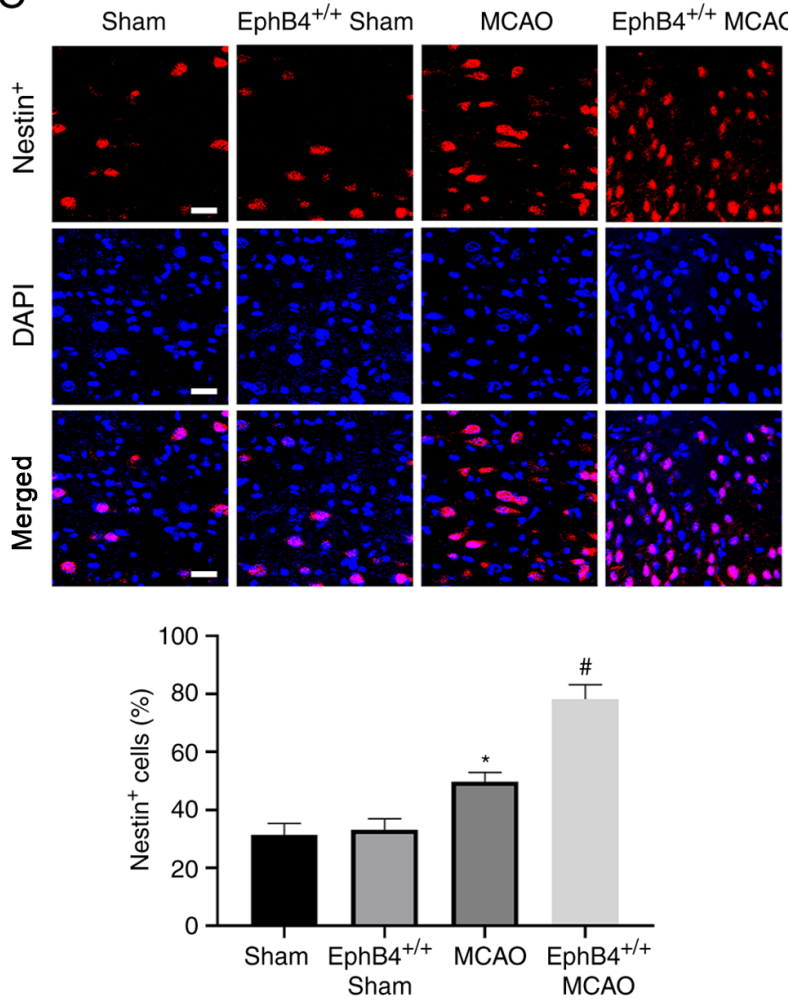

$\mathrm{E}$

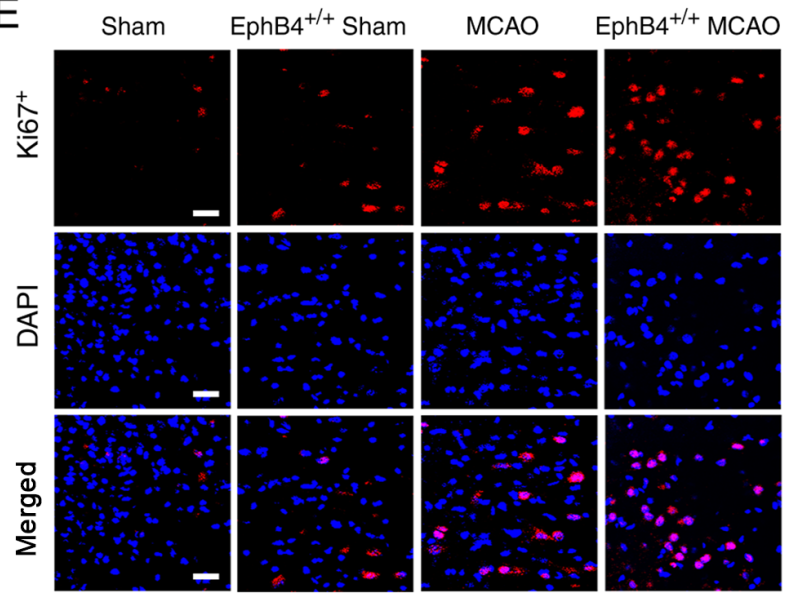

B

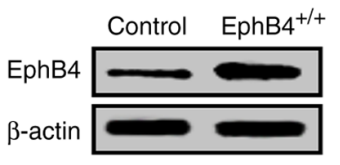

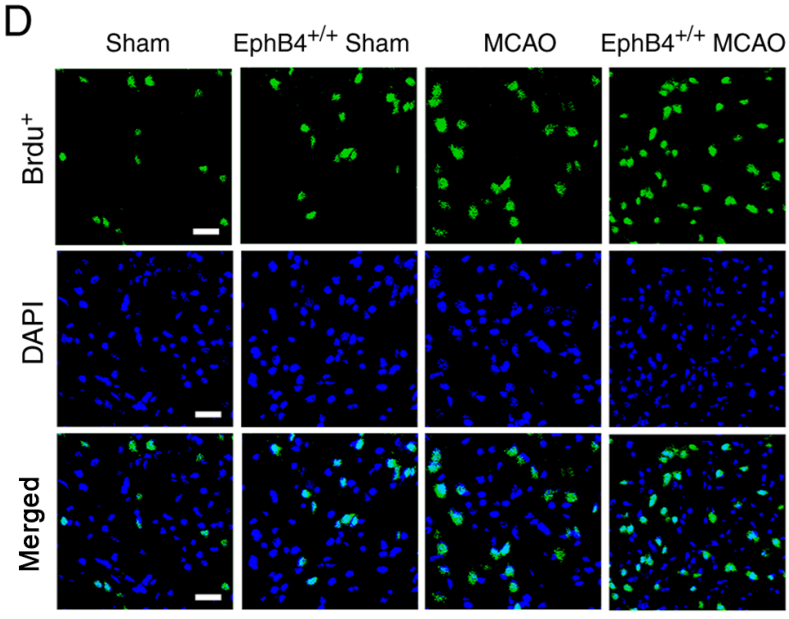
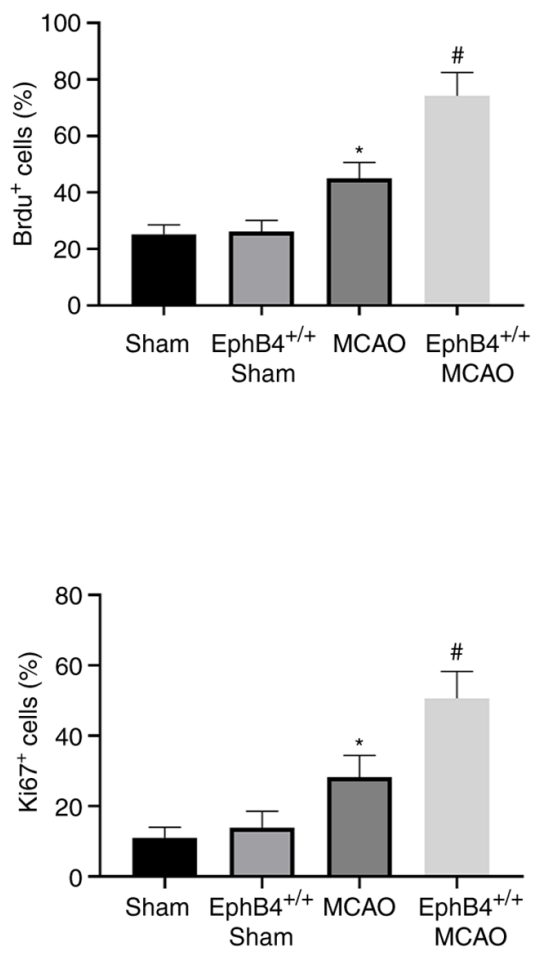

Figure 3. Overexpression of EphB4 enhances neuronal stem cell proliferation in the cortex at 7 days following MCAO. (A) Reverse transcription-quantitative PCR and (B) western blot analysis of EphB4 expression in EphB4 $4^{++}$mice and wild-type mice. (C) Images showing the immunostaining for Nestin ${ }^{+}$, and the bar graph presented the quantification of the number of Nestin ${ }^{+}$cells in the peri-infarct cortex. (D) Images showed the immunostaining for Brdu ${ }^{+}$and the bar graph showed the quantification of the number of $\mathrm{Brdu}^{+}$cells in the peri-infarct cortex. (E) Images showed the immunostaining for Ki67 ${ }^{+}$and the bar graph showed the quantification of the number of Ki67 cells in the peri-infarct cortex. Scale bar, $25 \mu \mathrm{m}$. $\mathrm{n}=5$ for each group. Data are presented as mean $\pm \mathrm{SD}$. ${ }^{*} \mathrm{P}<0.05$ vs. Sham; ${ }^{* *} \mathrm{P}<0.01$ vs. control; ${ }^{*} \mathrm{P}<0.05$ vs. MCAO. EphB4, EPH receptor B4; MCAO, middle cerebral artery occlusion; Brdu, bromodeoxyuridine.

progenitors $\left(\right.$ Sox $\left.2^{+}\right)$, neuroblasts $\left(\mathrm{DCX}^{+}\right)$and eventually mature neurons $\left(\mathrm{NeuN}^{+}\right)$. These results indicated the potential relationship between the EphB4 and neurogenesis.
Overexpression of EphB4 promotes NSC proliferation in the cerebral cortex of MCAO model mice. To confirm whether EphB4 modulated the proliferation of nerve cells, NSCs 

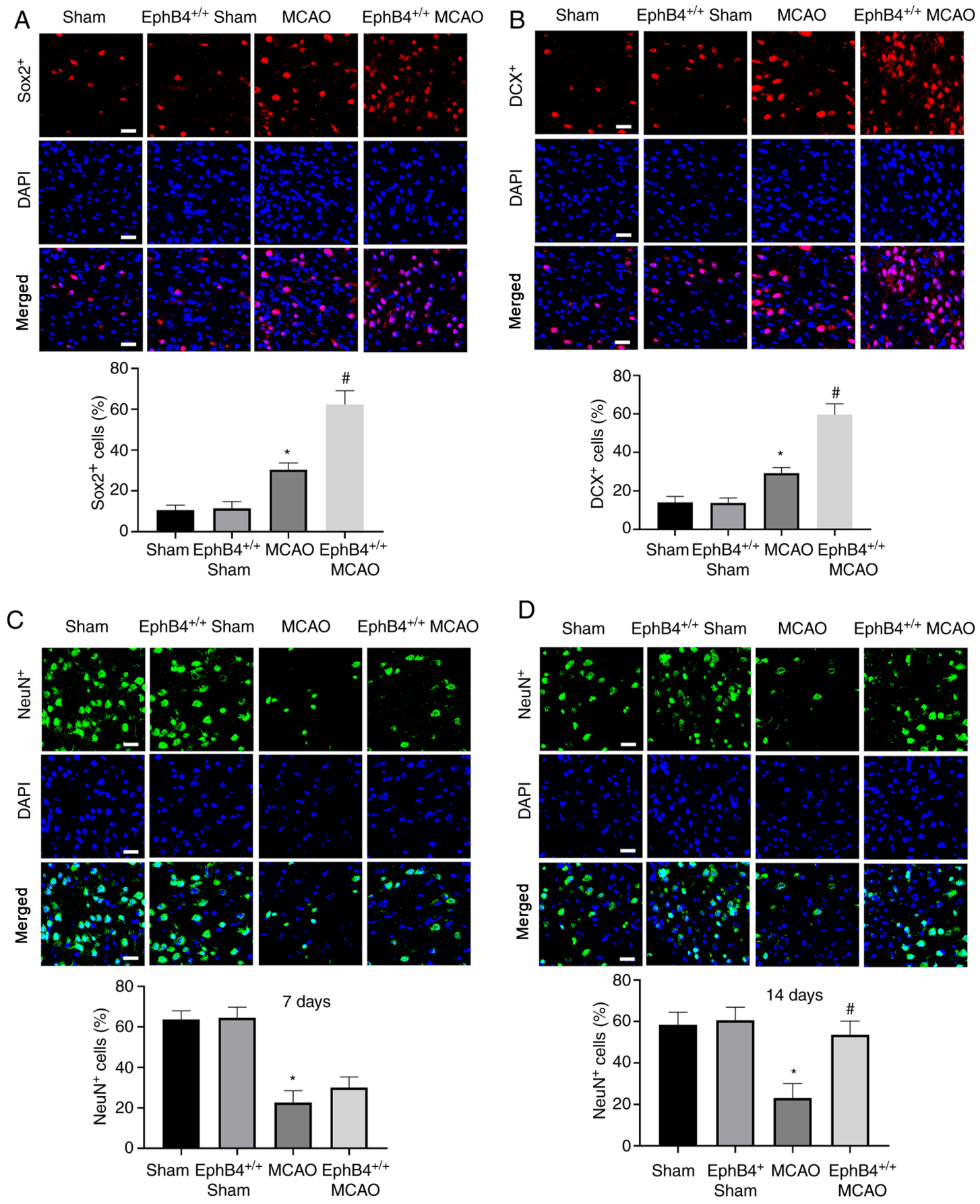

Figure 4. Overexpression of EphB4 promotes neuronal stem cell differentiation in the cortex following MCAO. Images of the immunostaining for (A) Sox $2^{+}$ and (B) DCX+ cells, and the bar graph showed the quantification of the number of Sox $2^{+}$and $\mathrm{DCX}^{+}$cells in the peri-infarct cortex at 7 days after MCAO. Images of the immunostaining for $\mathrm{NeuN}^{+}$cells and the bar graph showed the quantification of the number of $\mathrm{NeuN}^{+}$cells in the peri-infarct cortex at (C) 7 day and (D) 14 day after MCAO. Scale bar, $25 \mu \mathrm{m}$. $\mathrm{n}=5$ for each group. Data are presented as mean $\pm \mathrm{SD}$. ${ }^{\prime} \mathrm{P}<0.05$ vs. Sham; " $\mathrm{P}<0.05$ vs. MCAO. DCX, doublecortin; EphB4, EPH receptor B4; NeuN, neuronal nuclei; MCAO, middle cerebral artery occlusion.

labelled with Nestin ${ }^{+}$, and newborn cells labeled with $\mathrm{Brdu}^{+}$ or $\mathrm{Ki}^{6} 7^{+}$were observed in the peri-infarct cortex 7 days after MCAO using an immunofluorescence assay. EphB4 expression was measured via RT-qPCR and western blotting in $\mathrm{EphB}^{++} /^{+}$mice prior to MCAO. The results demonstrated that EphB4 was significantly elevated in EphB $4^{+/+}$mice compared with wild-type mice (Fig. 3A and B). Immunofluorescence results revealed that there were no differences in the number of positive cells $\left(\mathrm{Nestin}^{+}, \mathrm{Brdu}^{+}\right.$and $\mathrm{Ki}^{+} 7^{+}$) between sham mice and the EphB4 $4^{++}$sham mice, while the number of these positive cells was significantly increased in MCAO mice vs. sham-operated mice. Overexpression of EphB4 further enhanced the number of these positive cells in MCAO model mice (Fig. 3C-E). Overall, these data indicated that overexpression of EphB4 promoted NSC proliferation after focal cerebral ischemia in vivo.

Overexpression of EphB4 promotes NSC differentiation in the cerebral cortex of MCAO model mice. Sox 2 is an important molecular marker of adult NSCs (24). DCX is 



G

$\mathrm{H}$
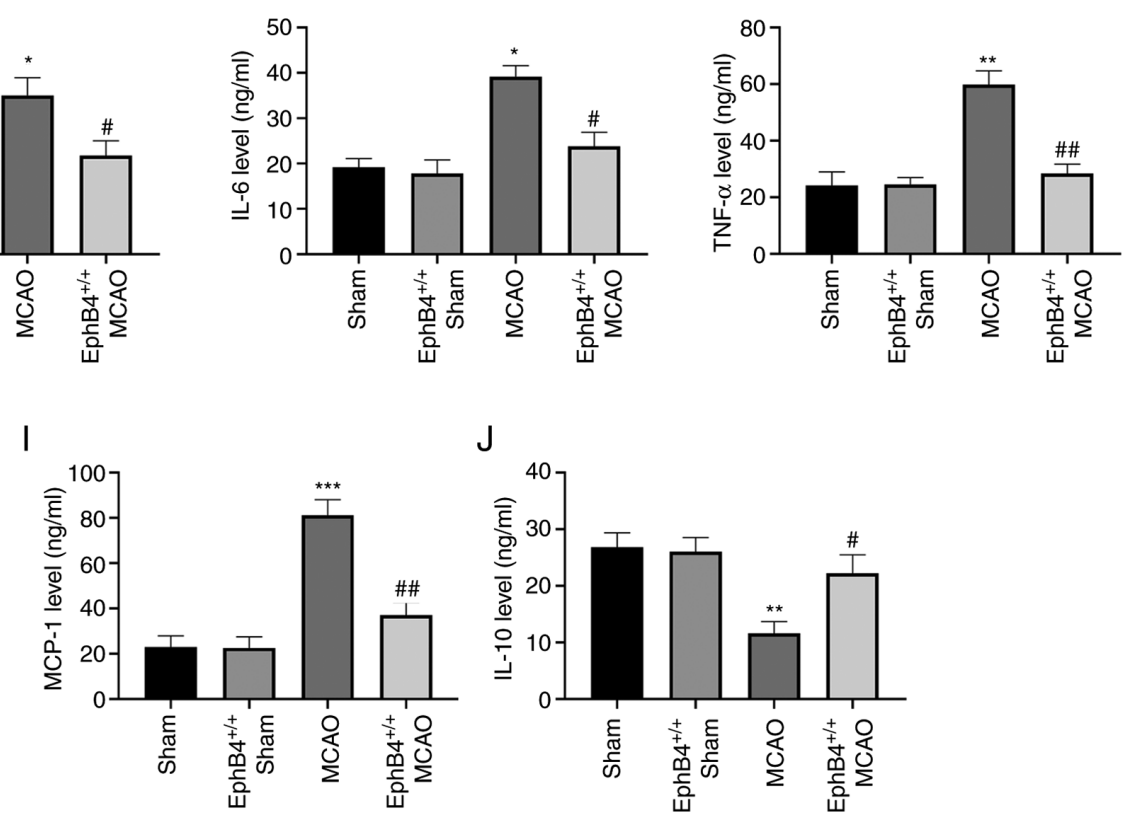

Figure 5. Overexpression of EphB4 inhibits the inflammatory cytokine levels MCAO model mice. The levels of (A) IL-1 $\beta$, (B) IL-6, (C) TNF- $\alpha$, (D) MCP-1 and (E) IL-10 in the cortex around the infarcted zone were detected via ELISA at 1 day after MCAO. The levels of (F) IL-1 $\beta$, (G) IL-6, (H) TNF- $\alpha$, (I) MCP-1 and (J) IL-10 in the plasma of MCAO model mice were detected via ELISA at 1 day. $n=5$ for each group. Data are presented as mean $\pm \mathrm{SD}$. ${ }^{*} \mathrm{P}<0.05,{ }^{* *} \mathrm{P}<0.01$, ${ }_{* * * *} \mathrm{P}<0.001$ vs. Sham; ${ }^{*} \mathrm{P}<0.05,{ }^{\# \#} \mathrm{P}<0.01$ vs. MCAO. EphB4, EPH receptor B4; MCAO, middle cerebral artery occlusion; MCP-1, monocyte chemoattractant protein 1.

a microtubule-associated protein expressed in immature neurons, which is essential for neuronal migration and differentiation (25). Thus, Sox $2^{+}, \mathrm{DCX}^{+}$and $\mathrm{NeuN}^{+}$expression in the peri-infarct cortex 7 days after ischemia reperfusion was detected. As show in Fig. 4A and B, Sox $2^{+}$and $\mathrm{DCX}^{+}$cells were significantly increased at 7 days in MCAO model mice compared with sham-operated mice. EphB4 overexpression further increased the number of Sox $2^{+}$and $\mathrm{DCX}^{+}$cells compared with the MCAO model mice. However, $\mathrm{NeuN}^{+}$ cells exhibited no significant difference between MCAO and EphB4 $4^{++}$MCAO groups at 7 days (Fig. 4C). However, at 14 days, the number of $\mathrm{NeuN}^{+}$cells was significantly increased in the EphB4 ${ }^{+/} \mathrm{MCAO}$ model mice compared with the MCAO model mice (Fig. 4D), suggesting that restoration of EphB4 promoted NSC differentiation after focal cerebral ischemia in vivo.

Overexpression of EphB4 attenuates the inflammatory response in MCAO model mice. To investigate the effect of EphB4 on the inflammation injury in ischemic stroke model 


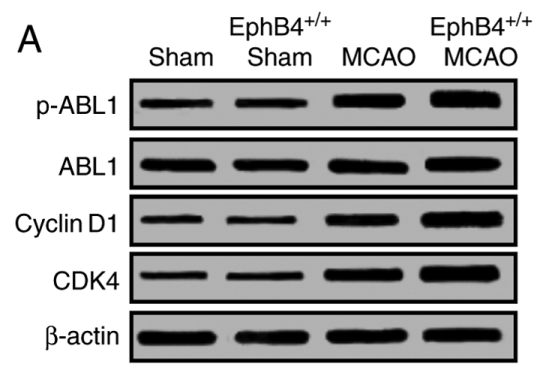

C

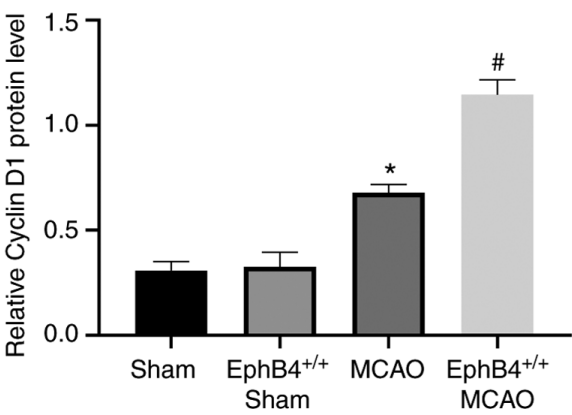



D

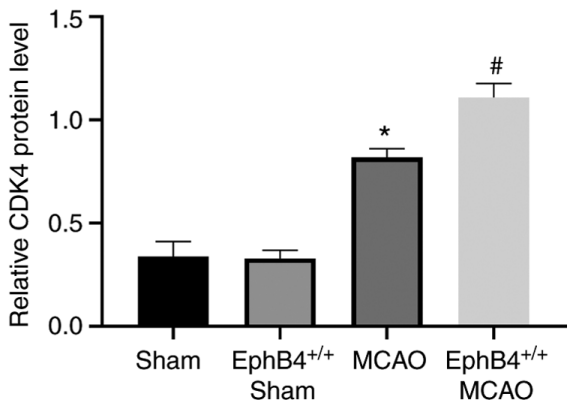

Figure 6. Overexpression of EphB4 activates the ABL1/Cyclin D1 signaling pathway in the cerebral cortex of MCAO model mice. (A) Representative image of immunoblots for ABL1, p-ABL1, Cyclin D1 and CDK4 in the cortex of mice at 7 days after MCAO. Semi-quantitative analysis of (B) p/ABL1, (C) Cyclin D1/ $\beta$-actin and (D) $\mathrm{CDK} 4 / \beta$-actin in the cortex of mice at 7 days after MCAO. $\mathrm{n}=5$ for each group. Data are presented as mean $\pm \mathrm{SD}$. ${ }^{*} \mathrm{P}<0.05$ vs. Sham; ${ }^{\#} \mathrm{P}<0.05 \mathrm{vs}$. MCAO. EphB4, EPH receptor B4; MCAO, middle cerebral artery occlusion; ABL1, ABL proto-oncogene 1, non-receptor tyrosine kinase; p-, phosphorylated.

mice, a series of inflammatory cytokines, including IL-1 $\beta$, IL-6, TNF- $\alpha$, IL-10 and MCP-1, in the tissues of cerebral cortex and the plasma of mice were evaluated. The results demonstrated that the levels of IL- $1 \beta$, IL- 6 , TNF- $\alpha$ and MCP-1 were quickly increased in the tissues of MCAO group compared with sham operation group. However, the stroke-evoked enhancement of cytokine levels was markedly inhibited in EphB $4^{+}{ }^{+}$mice after MCAO (Fig. 5A-D). Interestingly, the level of IL-10, generally regarded as an anti-inflammatory cytokine (26), was significantly decreased after stroke; however, the low level of IL-10 was significantly increased in the EphB $4^{+} /{ }^{+} \mathrm{MCAO}$ group (Fig. 5E). Consistent with the aforementioned results, the levels of IL-1 $\beta$, IL-6, TNF- $\alpha$ and MCP-1 were quickly inhibited in the plasma of EphB $4^{+/+} \mathrm{MCAO}$ model mice, which were enhanced by MCAO operation (Fig. 5F-I). However, the level of IL-10 was significantly decreased in MCAO mice vs. sham-operated mice, and EphB $4^{+}{ }^{+}$increased the low level of IL-10 in MCAO model mice (Fig. 5J). These results suggest that overexpression of EphB4 attenuated the MCAO-induced inflammatory response.

EphB4 activates the ABL1/Cyclin D1 signaling pathway in the cerebral cortex of MCAO model mice. To assess the potential mechanism of EphB4 in neurogenesis, the related proteins of the ABL1/Cyclin D1 signaling pathway were examined. As shown in Fig. 6A-D, the expression levels of p-ABL1, Cyclin D1 and CDK4 showed a significant increase in the MCAO-treated ischemia mice compared with the sham-operated group. Moreover, compared with the MCAO-treated ischemic mice, the abovementioned protein expression levels were significantly increased in the EphB $4^{+/^{+}} \mathrm{MCAO}$ model mice at 7 days after ischemia (Fig. 6B-D). These results indicated that overexpression of EphB4 activated the ABL1/Cyclin D1 signaling pathway, thereby promoting cell proliferation and differentiation in mice after ischemia stroke.

\section{Discussion}

Ischemic strokes result in numerous deaths and leave survivors with significant disability, despite various reasonable treatments (27). Neurogenesis has been proven to be a primary neurovascular response during stroke recovery $(28,29)$. In the present study, it was found that overexpression of EphB4 promoted the proliferation and differentiation of NSCs in the cerebral cortex by modulating the ABL1/Cyclin D1 signaling pathway after cerebral ischemia, suggesting that EphB4 may be an effective strategic target for improving neurological dysfunction in ischemic stroke.

EphB4 tyrosine kinase receptor and its ephrinB2 ligand have been identified as important regulators of tumor cell proliferation, migration and differentiation (30-32). For instance, EphB4 was highly expressed in hepatocellular carcinoma and knockdown of EphB4 inhibited cell proliferation and migration and tumor growth (33). Kadife et al (34) discovered that a high expression level of EphB4 facilitated colorectal cancer cell migration and tumor growth. Interestingly, EphB4 was reported to be upregulated after stroke, and was suggested to be involved in neoangiogenesis and neuronal survival $(35,36)$, which was consistent with the present findings that EphB4 was significantly increased in mice after MCAO. A previous study also revealed that EphB4 was expressed in NSCs and instructed NSC neuronal differentiation in the subgranular zone (37). The present study demonstrated that EphB4 was expressed in NSCs and may participate in the differentiation of NSC in the cortex following MCAO. 
Brdu is usually employed to label cells in the cell cycle of S phase (38). Ki67 is a nuclear protein associated with ribosomal RNA transcription that acts as a marker for cell proliferation (39). A previous study showed that Nestin ${ }^{+}$cells can be observed extensively in restricted regions where they may serve as a niche of stem/progenitor cells with the capacity for proliferation and differentiation in the adult mouse brain (40). Therefore, in the present study, the increased levels of Nestin ${ }^{+}$, $\mathrm{Ki}^{+} 7^{+}$and $\mathrm{Brdu}^{+}$cells in the peri-infarct cortex of the ischemia-treated mice indicated the endogenous NSC response following MCAO. In the EphB4 overexpression group, the increase of $\mathrm{Nestin}^{+}, \mathrm{Ki} 7^{+}$and $\mathrm{Brdu}^{+}$cells was further enhanced. These results indicated that EphB4 overexpression promotes cell proliferation post-ischemia.

Sox2, a member of the Sox family of transcription factors, is highly expressed during the development of embryonic stem cells and adult NSCs, and is considered to be the key to the proliferation and differentiation of NSCs (41). DCX, a protein facilitating microtubule polymerization, is expressed in migrating neuroblasts and immature neurons, and can be classified as a marker for adult neurogenesis (42). NeuN is a neuronal protein and a neuron marker utilized to specifically label mature neurons (43). Hence, in the current study, the increased number of Sox $2^{+}, \mathrm{DCX}^{+}$and $\mathrm{NeuN}^{+}$cells in the cortex of the EphB $4^{+} /^{+} \mathrm{MCAO}$ model mice indicated that EphB4 may participate in promoting NSC differentiation into neurons post-ischemia. The upregulation of these neural cells is considered to contribute to functional recovery of brain.

The downstream factor of the ephrinB2/EphB4 signaling pathway, ABL1, binds to EphB4 in an activity-dependent manner (16). Previous findings have shown that ABL1 served an important role in the stimulation of neurogenesis (44). Moreover, ABL1 could mediate the signaling between EphB4 and Cyclin D1/CDK4 to regulate proliferation in NSCs (18). The current results revealed that overexpression of EphB4 increased the protein expression levels of p-ABL1, Cyclin D1 and CDK4, suggesting that EphB4 may promote neurogenesis after ischemic stroke via the ABL1/Cyclin D1 signaling pathway in vivo.

There were certain limitations in the present study. Firstly, the effect of EphB4 on neurogenesis was not assessed in vitro. Secondly, the level of EphB4 in patients with ischemic stroke was not examined and the association between EphB4 levels and lesion volume requires further study. The underlying mechanism of EphB4 on neurogenesis and neuroinflammation should also be investigated both in vitro and in vivo.

In conclusion, the present study demonstrated that restoration of EphB4 promoted cell proliferation and differentiation at 7 days after MCAO, and facilitated NSC directional differentiation into neurons at 14 days after MCAO. However, EphB4 upregulation inhibited neuroinflammation at 1 day after MCAO. Moreover, it was found that overexpression of EphB4 promoted the activation of the ABL1/Cyclin D1 signaling pathway. These findings suggested that EphB4 may be a valuable therapeutic target for ischemic stroke.

\section{Acknowledgements}

Not applicable.

\section{Funding}

No funding was received.

\section{Availability of data and materials}

The datasets used and/or analyzed during the present study are available from the corresponding author on reasonable request.

\section{Authors' contributions}

JW guaranteed the integrity of the entire study, performed the experiments and wrote the manuscript. ZZ, SF and XiaL constructed the MCAO model and collected brain tissues. ZZ, XinL and SW performed the data analysis and statistical analysis. LY designed the study, supervised the research and participated in reviewing the manuscript. All authors read and approved the final manuscript. JW and LY confirmed the authenticity of all the raw data.

\section{Ethics approval and consent to participate}

The study was approved by the Ethics Committee of Inner Mongolia Baogang Hospital (approval no. BG201802034YY).

\section{Patient consent for publication}

Not applicable.

\section{Competing interests}

The authors declare that they have no competing interests.

\section{References}

1. Feigin VL, Forouzanfar MH, Krishnamurthi R, Mensah GA, Connor M, Bennett DA, Moran AE, Sacco RL, Anderson L, Truelsen T, et al: Global and regional burden of stroke during 1990-2010: Findings from the global burden of disease study 2010. Lancet 383: 245-254, 2014.

2. Krishnamurthi RV, Ikeda T and Feigin VL: Global, regional and country-specific burden of ischaemic stroke, intracerebral haemorrhage and subarachnoid haemorrhage: A systematic analysis of the global burden of disease study 2017. Neuroepidemiology 54: 171-179, 2020.

3. Pires Monteiro S, Voogd E, Muzzi L, De Vecchis G, Mossink B, Levers M, Hassink G, Van Putten M, Le Feber J, Hofmeijer J and Frega M: Neuroprotective effect of hypoxic preconditioning and neuronal activation in a in vitro human model of the ischemic penumbra. J Neural Eng 18: 036016, 2021.

4. Doetsch F, Caillé I, Lim DA, Garcia-Verdugo JM and Alvarez-Buylla A: Subventricular zone astrocytes are neural stem cells in the adult mammalian brain. Cell 97: 703-716, 1999.

5. Bond AM, Ming GL and Song H: Adult mammalian neural stem cells and neurogenesis: Five decades later. Cell Stem Cell 17: 385-395, 2015.

6. Yan YP, Sailor KA, Lang BT, Park SW, Vemuganti R and Dempsey RJ: Monocyte chemoattractant protein-1 plays a critical role in neuroblast migration after focal cerebral ischemia. J Cereb Blood Flow Metab 27: 1213-1224, 2007.

7. Chen L, Qiu R, Li L, He D, Lv H, Wu X and Gu N: The role of exogenous neural stem cells transplantation in cerebral ischemic stroke. J Biomed Nanotechnol 10: 3219-3230, 2014.

8. Yamashita T, Ninomiya M, Hernandez Acosta $P$, García-Verdugo JM, Sunabori T, Sakaguchi M, Adachi K, Kojima T, Hirota Y, Kawase T, et al: Subventricular zone-derived neuroblasts migrate and differentiate into mature neurons in the post-stroke adult striatum. J Neurosci 26: 6627-6636, 2006 
9. Kaneko N and Sawamoto K: Adult neurogenesis and its alteration under pathological conditions. Neurosci Res 63: 155-164, 2009.

10. Dong X, Gao J, Zhang CY, Hayworth C, Frank M and Wang Z: Neutrophil membrane-derived nanovesicles alleviate inflammation to protect mouse brain injury from ischemic stroke. ACS Nano 13: 1272-1283, 2019.

11. Yang S, Wang H, Yang Y, Wang R, Wang Y, Wu C and Du G: Baicalein administered in the subacute phase ameliorates ischemia-reperfusion-induced brain injury by reducing neuroinflammation and neuronal damage. Biomed Pharmacother 117: $109102,2019$.

12. Retraction: Roles of Eph/ephrin bidirectional signaling during injury and recovery of the central nervous system. Neural Regen Res 13: 2140, 2018.

13. Knöll B and Drescher U: Ephrin-As as receptors in topographic projections. Trends Neurosci 25: 145-149, 2002.

14. del Valle K, Theus MH, Bethea JR, Liebl DJ and Ricard J: Neural progenitors proliferation is inhibited by EphB3 in the developing subventricular zone. Int J Dev Neurosci 29: 9-14, 2011.

15. Conover JC, Doetsch F, Garcia-Verdugo JM, Gale NW, Yancopoulos GD and Alvarez-Buylla A: Disruption of Eph/ephrin signaling affects migration and proliferation in the adult subventricular zone. Nat Neurosci 3: 1091-1097, 2000.

16. Noren NK, Foos G, Hauser CA and Pasquale EB: The EphB4 receptor suppresses breast cancer cell tumorigenicity through an Abl-Crk pathway. Nat Cell Biol 8: 815-825, 2006.

17. Ferguson BD,Liu R, Rolle CE, Tan YH, Krasnoperov V, Kanteti R, Tretiakova MS, Cervantes GM, Hasina R, Hseu RD, et al: The EphB4 receptor tyrosine kinase promotes lung cancer growth: A potential novel therapeutic target. PLoS One 8: e67668, 2013.

18. Liu T, Zeng X, Sun F, Hou H, Guan Y, Guo D, Ai H, Wang W and Zhang G: EphB4 regulates self-renewal, proliferation and neuronal differentiation of human embryonic neural stem cells in vitro. Cell Physiol Biochem 41: 819-834, 2017.

19. Chen ST, Hsu CY, Hogan EL, Maricq H and Balentine JD: A model of focal ischemic stroke in the rat: Reproducible extensive cortical infarction. Stroke 17: 738-743, 1986.

20. Livak KJ and Schmittgen TD: Analysis of relative gene expression data using real-time quantitative PCR and the 2(-Delta Delta C(T)) method. Methods 25: 402-408, 2001.

21. Yao RQ, Zhang L, Wang W and Li L: Cornel iridoid glycoside promotes neurogenesis and angiogenesis and improves neurological function after focal cerebral ischemia in rats. Brain Res Bull 79: 69-76, 2009.

22. López-Juárez A, Remaud S, Hassani Z, Jolivet P, Pierre Simons J, Sontag T, Yoshikawa K, Price J, Morvan-Dubois G and Demeneix BA: Thyroid hormone signaling acts as a neurogenic switch by repressing Sox 2 in the adult neural stem cell niche. Cell Stem Cell 10: 531-543, 2012.

23. Moraga A, Pradillo JM, Garcia-Culebras A, Palma-Tortosa S, Ballesteros I, Hernández-Jiménez M, Moro MA and Lizasoain I Aging increases microglial proliferation, delays cell migration, and decreases cortical neurogenesis after focal cerebral ischemia. J Neuroinflammation 12: 87, 2015.

24. Marei HE, Shouman Z, Althani A, Afifi N, A AE, Lashen S, Hasan A, Caceci T, Rizzi R, Cenciarelli C and Casalbore P. Differentiation of human olfactory bulb-derived neural stem cells toward oligodendrocyte. J Cell Physiol 233: 1321-1329, 2018

25. Dayer AG, Cleaver KM, Abouantoun T and Cameron HA: New GABAergic interneurons in the adult neocortex and striatum are generated from different precursors. J Cell Biol 168: 415-427, 2005.

26. Carlson KN, Pavan-Guimaraes J, Verhagen JC, Chlebeck P, Verhoven B, Jennings H, Najmabadi F, Liu Y, Burlingham W, Capitini CM and Al-Adra D: IL-10 and TGF- $\beta$ cytokines decrease immune activation during normothermic ex vivo machine perfusion of the rat liver. Liver Transpl: Jun 12, 2021 (Epub ahead of print).

27. Onwuekwe I and Ezeala-Adikaibe B: Ischemic stroke and neuroprotection. Ann Med Health Sci Res 2: 186-190, 2012

28. Delavaran H, Sjunnesson H, Arvidsson A, Lindvall O, Norrving B, van Westen D, Kokaia Z and Lindgren A: Proximity of brain infarcts to regions of endogenous neurogenesis and involvement of striatum in ischaemic stroke. Eur J Neurol 20: $473-479,2013$
29. Ohira K, Furuta T, Hioki H, Nakamura KC, Kuramoto E, Tanaka Y, Funatsu N, Shimizu K, Oishi T, Hayashi M, et al: Ischemia-induced neurogenesis of neocortical layer 1 progenitor cells. Nat Neurosci 13: 173-179, 2010.

30. Wan X, Saban DV, Kim SN, Weng Y, Dammann P, Keyvani K, Sure U and Zhu Y: PDCD10-deficiency promotes malignant behaviors and tumor growth via triggering EphB4 kinase activity in glioblastoma. Front Oncol 10: 1377, 2020.

31. Tang Y, Lei Y, Huang S, Li Z, Chen X, Luo H, Cheng C, Chen J, Zou $X$ and Chen $X$ : Pristimerin exacerbates cellular injury in conditionally reprogrammed patient-derived lung adenocarcinoma cells by aggravating mitochondrial impairment and endoplasmic reticulum stress through EphB4/CDC42/ N-WASP signaling. Oxid Med Cell Longev 2020: 7409853 , 2020.

32. Bhatia S, Bukkapatnam S, Van Court B, Phan A, Oweida A, Gadwa J, Mueller AC, Piper M, Darragh L, Nguyen D, et al: The effects of ephrinB2 signaling on proliferation and invasion in glioblastoma multiforme. Mol Carcinog 59: 1064-1075, 2020.

33. Zhu M, Gong Z, Wu Q, Su Q, Yang T, Yu R, Xu R and Zhang Y: Homoharringtonine suppresses tumor proliferation and migration by regulating EphB4-mediated $\beta$-catenin loss in hepatocellular carcinoma. Cell Death Dis 11: 632, 2020.

34. Kadife E, Ware TMB, Luwor RB, Chan STF, Nurgali K and Senior PV: Effects of EphB4 receptor expression on colorectal cancer cells, tumor growth, vascularization and composition. Acta Oncol 57: 1043-1056, 2018.

35. Yoon Y, Voloudakis G, Doran N, Zhang E, Dimovasili C, Chen L, Shao Z, Darmanis S, Tang C, Tang J, et al: PS1 FAD mutants decrease ephrinB2-regulated angiogenic functions, ischemia-induced brain neovascularization and neuronal survival. Mol Psychiatry: Jun 15,2020 (Epub ahead of print).

36. Ghori A, Freimann FB, Nieminen-Kelhä M, Kremenetskaia I, Gertz K, Endres M and Vajkoczy P: EphrinB2 activation enhances vascular repair mechanisms and reduces brain swelling after mild cerebral ischemia. Arterioscler Thromb Vasc Biol 37: 867-878, 2017.

37. Ashton RS, Conway A, Pangarkar C, Bergen J, Lim KI, Shah P, Bissell M and Schaffer DV: Astrocytes regulate adult hippocampal neurogenesis through ephrin-B signaling. Nat Neurosci 15: 1399-1406, 2012.

38. Kempermann G, Gast D, Kronenberg G, Yamaguchi M and Gage FH: Early determination and long-term persistence of adult-generated new neurons in the hippocampus of mice. Development 130: 391-399, 2003.

39. Schaefer BM, Wallich R, Schmolke K, Fink W, Bechtel M, Reinartz J and Kramer MD: Immunohistochemical and molecular characterization of cultured keratinocytes after dispase-mediated detachment from the growth substratum. Exp Dermatol 9: 58-64, 2000.

40. Namiki J, Suzuki S, Masuda T, Ishihama Y and Okano H: Nestin protein is phosphorylated in adult neural stem/progenitor cells and not endothelial progenitor cells. Stem Cells Int 2012: 430138, 2012.

41. Ferri AL, Cavallaro M, Braida D, Di Cristofano A, Canta A, Vezzani A, Ottolenghi S, Pandolfi PP, Sala M, DeBiasi S and Nicolis SK: Sox 2 deficiency causes neurodegeneration and impaired neurogenesis in the adult mouse brain. Development 131: 3805-3819, 2004

42. Brown JP, Couillard-Després S, Cooper-Kuhn CM, Winkler J, Aigner L and Kuhn HG: Transient expression of doublecortin during adult neurogenesis. J Comp Neurol 467: 1-10, 2003.

43. Dachet F, Bagla S, Keren-Aviram G, Morton A, Balan K, Saadat L, Valyi-Nagy T, Kupsky W, Song F, Dratz E and Loeb JA: Predicting novel histopathological microlesions in human epileptic brain through transcriptional clustering. Brain 138: 356-370, 2015.

44. Schlatterer SD, Suh HS, Conejero-Goldberg C, Chen S, Acker CM, Lee SC and Davies P: Neuronal c-Abl activation leads to induction of cell cycle and interferon signaling pathways. J Neuroinflammation 9: 208, 2012.

This work is licensed under a Creative Commons Attribution-NonCommercial-NoDerivatives 4.0 International (CC BY-NC-ND 4.0) License. 